ارزيابى يتانسيل دكر آسيبى عصاره آبى اندامهاى هوايى علفهرز تاتوره ( Datura

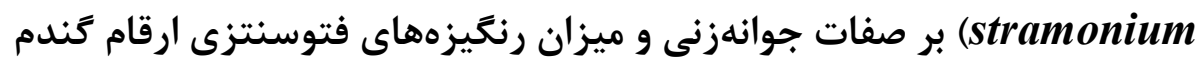
وحدت رجايى '، ابراهيم غلامعلى يور علمدارى r،"، زينب اورسجى '، معصومه نعيمى '،

$$
\text { جكيده مبسوط }
$$

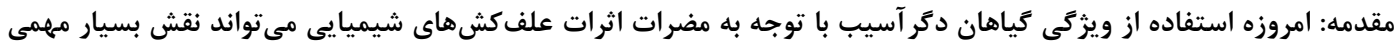

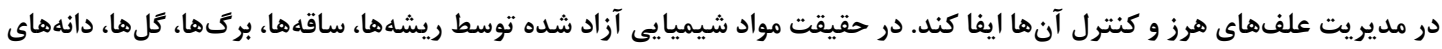

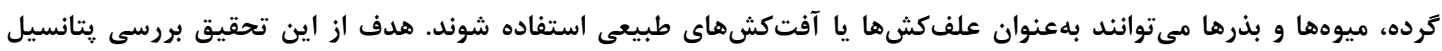

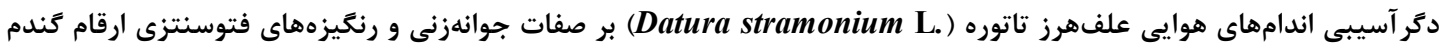

مواد و روشها: بهمنظور بررسى يتانسيل دكر آسيبى عصاره آبى اندامهاى مختلف علفهرز تاتوره نظير ساقه، برى، ميوه و

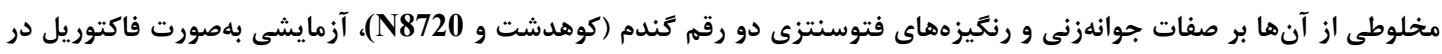

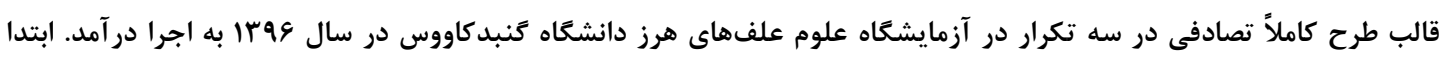

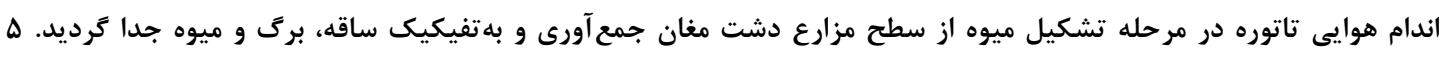

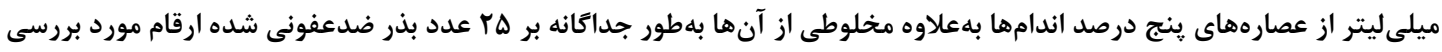

اعمال شد.

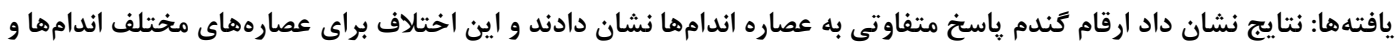

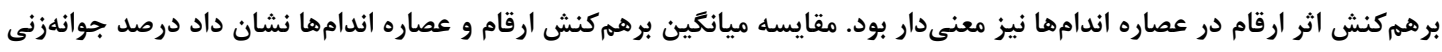

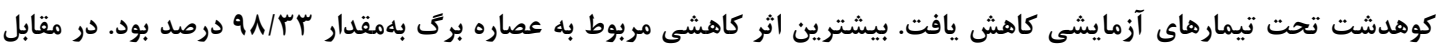

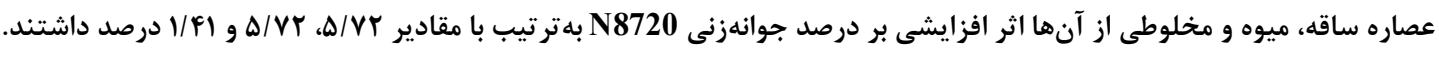

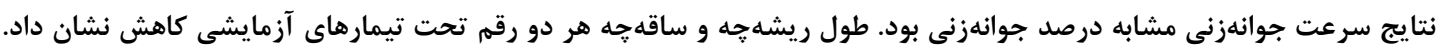

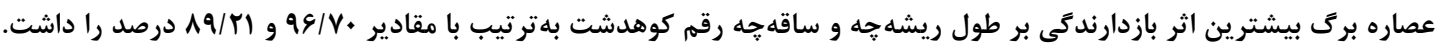

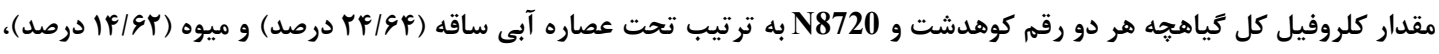

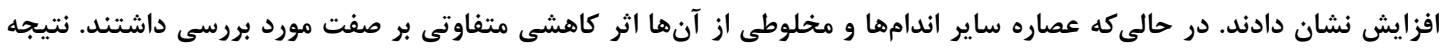

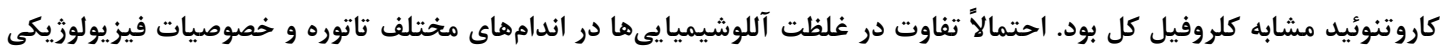

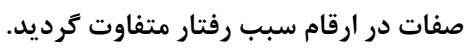

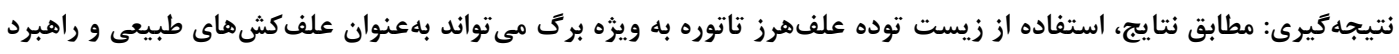

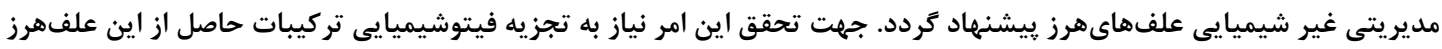
مىباشد. وازههاى كليدى: ارقام كوهدشت و N8720، اندام برك، بنيه بذر، دكر آسيبى، كاروتنوئيد، كلروفيل كل جنبdهاى نوآورى: ا- عصاره اندامهاى مختلف علفهرز تاتوره، اثرات متفاوتى بر صفات جوانهزنى و ميزان رنخيزههاى كلروفيلى و كاروتنوئيدى هر دو رقمم كوهدشت و N8720 دارند. ץ- عصاره برك تاتوره، صفات جوانهزنى و ميزان رنكَيزهاى كلروفيلى و كاروتنوئيدى كياهجههاى رقم كوهدشت را به مقدار زيادى كاهش r- استفاده از عصاره علفهرز تاتوره مىتواند انتخاب مناسبى براى پِيدايش علفكشهاى طبيعى باشد.

http://dorl.net/dor/20.1001.1.23831251.1397.5.2.5.0

http://dx.doi.org/10.29252/yujs.5.2.29

CrossMark
' دانش آموخته كارشناسى ارشد رشته شناسايى و مبارزه با علفهاى هرز دانشكده كشاورىى

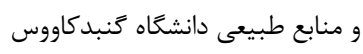

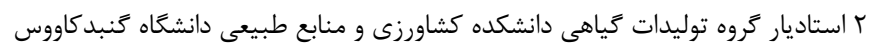

eg.alamdari@gonbad.ac.ir : رايانامه نويسنده مسئول:"

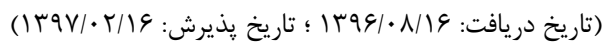




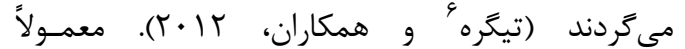

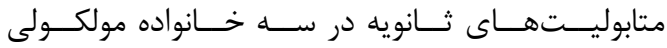

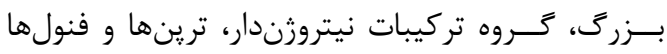

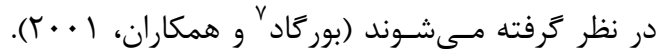

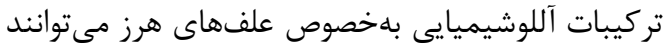

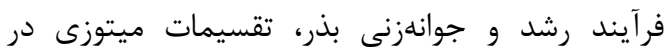

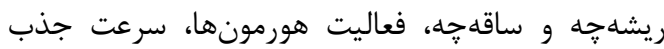

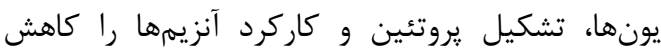

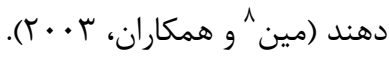

در زمينه دخرآسيبى علفهاى هرز تحقيقات زيادى

كزارش شده است، اما تحقيقات در زمينه برخى از

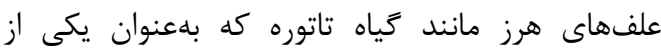

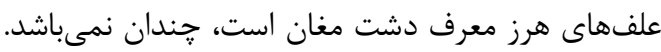

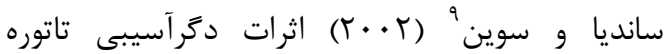
Oryza روى برنج (Datura stramonium) و سوروف (sativa بررسى قرار دادند. نتايج اين محققين نشان داد كه

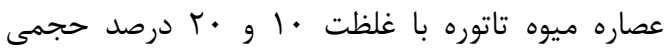

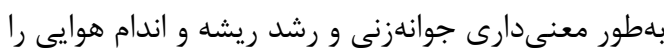

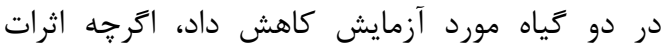

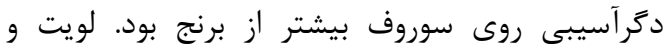

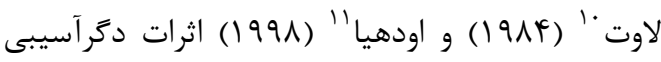

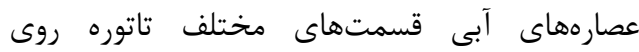
جوانهزنى، رشد نخود و برنج راكزارش نمودند.

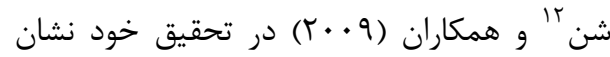
دادند كه علفهاى هرز مختلف از جمله سلمه تره Datura ) (Chenopodium album) (Stramonium و تاجريزى (Solanum nigrum)، روى (Chopodium كياهجههاى كندم، خيار و تربجه اثرات دَّر آسيبى دارند. نتايج آنان نشان داد كه عصاره برك و ساقه تاجريزى و و تربات

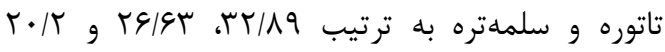
درصد، اثر بازدارندگى روى رشد كياهجه محصولات فوق تئن

\footnotetext{
${ }^{6}$ Tigre

${ }^{7}$ Bourgaud

${ }^{8}$ Min

${ }^{9}$ Sondhia and Swain

${ }^{10}$ Levitt and Lovett

${ }^{11}$ Oudhia

${ }^{12}$ Shen
}

مقلهمه

يكى از دلايل عمده كاهش محصول در زياهان زراعى هجوم علفهاى هرز است. علفهاى هرز با رقابت بر سر منابع، مانع از دسترسى مطلوب كياه زراعى به به اين منابع شده و در نتيجه باعث كاهش توليد و افزايش مايش

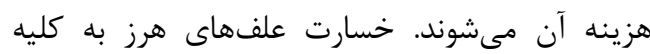

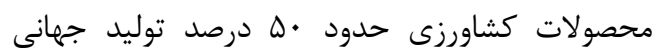

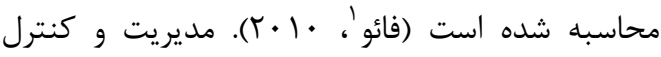
علفهاى هرز از برنامههاى به زراعى است كه در افزايش

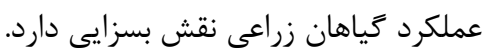

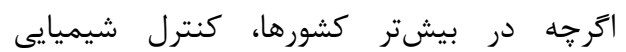
علفهاى هرز در حال انجام است ولى كاهش كيفيت كياهان زراعى، هزينه بالاى كنترل علفهاى هرز،

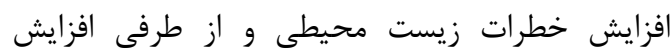
مقاومت علفهاى هرز به علفكشها بيانگر ضرورت تجديد نظر در روشهاى كنترل علفهاى هرز است

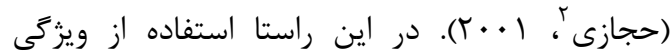

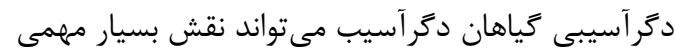
در مديريت و كنترل علفهاى هرز ايفا كند (راشد

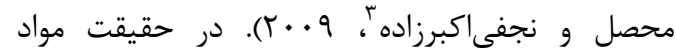
شيميايى آزاد شده توسط برگها، ساقهها، ريشهها،

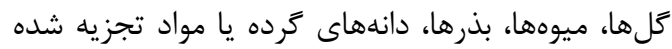

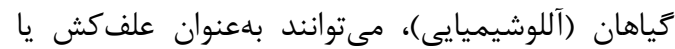

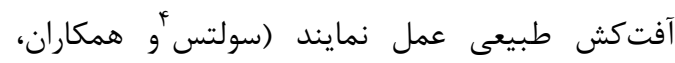

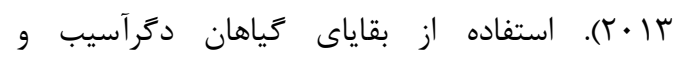
عصارههاى آنان و همجنين توليد گياهان زراعى واجد خصوصيات دَرآسيبى از طريق تكنيكهاى اصلاح نباتات از روشهاى نوين در مديريت علفهاى هرز است

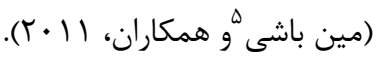

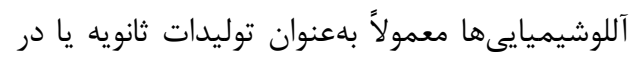
مسيرهاى اصلى متابوليسم در زياهان توليد مىشوند. اين مواد بهصورت محلول، در اثر شستشو از زياه، ترشحات ريشهاى، بهصورت گاز از سطح زياه و تجزيه بقاياى باقى مانده در سطح خاى در درئه دحيط آزاد

\footnotetext{
${ }^{1} \mathrm{FAO}$

${ }^{2}$ Hejazi

${ }^{3}$ Rashed-Mohassel and Najafi Akbarzadeh

${ }^{4}$ Soltys

${ }^{5}$ Min Bashi
} 
مىباشد. بنابراين با توجه به نياز مبرم به تركيبات با

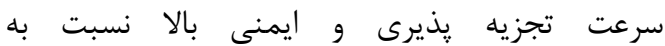
علفكشهاى سنتزى، بهرهورى از خاصيت ديرى درآسيبى

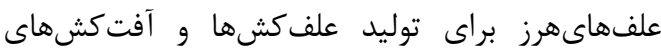
طبيعى ضرورى مىباشد. بنابراين هدف از تحقيق حاضر، ارزيابى يتانسيل دخرآسيبى عصارههاى اندامهاى مختلف

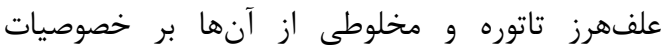
جوانهزنى و ميزان رنكَيزهاى فتوسنتزى ارقام كندم

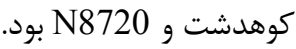

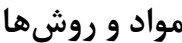

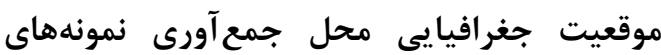
كياهى و آمادهسازى آنها در اين آزمايش علفهرز تاتوره در مرحله تشكيل ميوه از دشت مغان از توابع استان اردبيل با مساحت lQDF

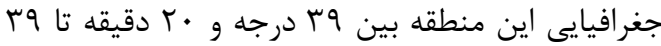

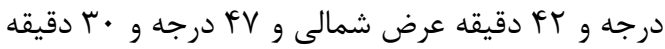
تا ب Y درجه و و •l دقيقه طول شرقى از نصفالنهاركرينويج واقع شده و هأ متر ارتفاع از سطح

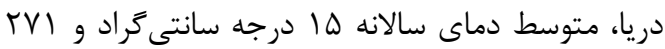
ميلىمتر بارش در طول سال مى باشد. علفهرز تاتوره در

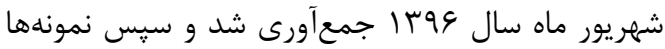

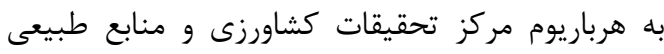

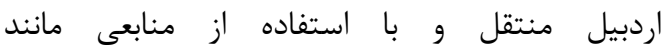

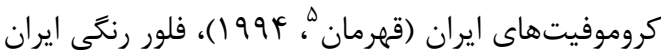
ايران (قهرمان، 1999-1994) مورد ارزيابى قرار كرفت. ابتدا اندامهاى مختلف تاتوره شامل ساقه، برك، ميوه به تفكيك از يكديگر جدا شد، سيس جهت برداشتن

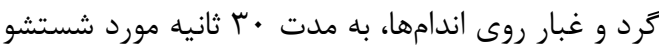

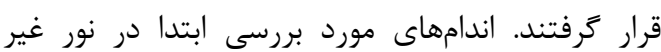

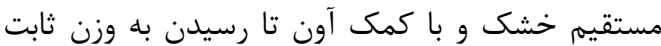

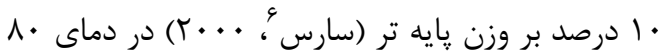

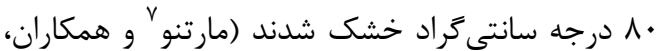

${ }^{5}$ Ghareman

${ }^{6}$ Caceres

${ }^{7}$ Martinov

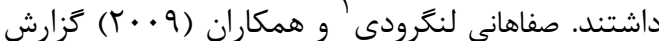
كردند كه علفهاى هرز توق (Xanthium spp)، تلخه و يير بهار (Solanum spp) دكرآسيبى قوى بر كندم دارند.

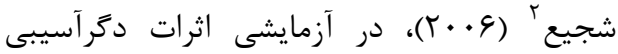
اندامهاى مختلف علفهرز تاتوره و توق شامل ريشه،

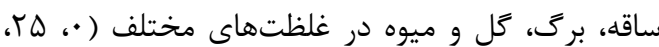

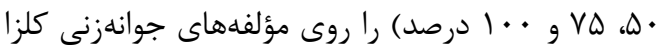

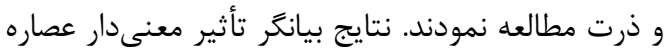
آبى غلظتهاى مختلف كليه اندامهاى مختلف تاتوره بر

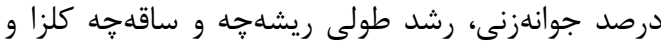
ذرت بود. عصاره ريشه تاتوره از بيشترين اثر بازدارندى دانى روى جوانهزنى ذرت (I/FV د درصد) در مقايسه با شاهد

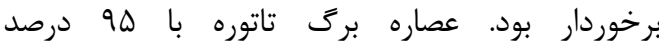

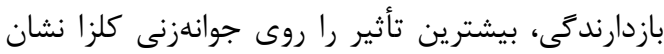

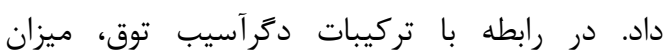
بازدارندكى عصاره برى بر درصد جوانهزنى كلزا بيشترين (9ه/VA)

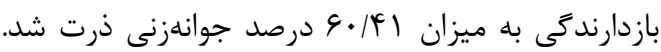
اما عصاره ساقه توق سبب بيشترين كاهش طولى رشد

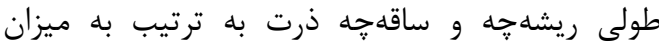

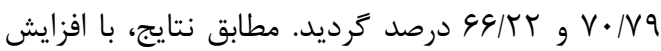
غلظتهاى عصاره هر اندام درصد جوانهزنى و رشد باند

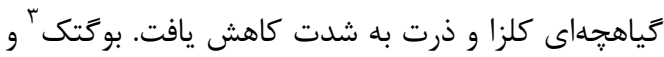

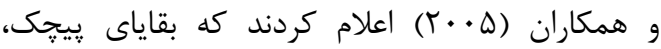

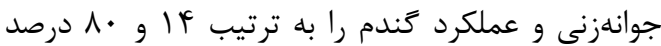

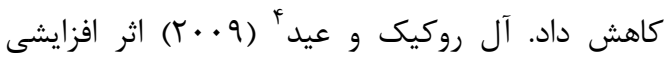

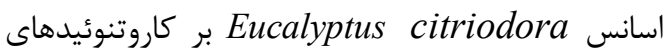

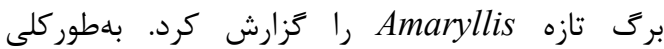
تركيبات ثانويه برخلاف تركيبات اوليه، گسترش محدودى در سلسله كياهى دارند كه اين تركيبات

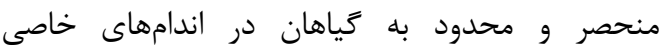
مىباشند. علفهرز تاتوره با دارا بودن انواع آلكالوئيدها از يراكنش و زيست توده بالايى در محصولات تابستانه

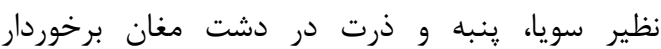

\footnotetext{
${ }^{1}$ Safahani Langeroudi

${ }^{2}$ Shajih

${ }^{3}$ Bogatek

${ }^{4}$ El-Rokiek and Eid
} 
$\mathrm{GP}=\sum_{i=0}^{n}\left(\frac{n i}{n}\right) \times 100$

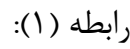

كه در آن، GP: درصد جوانهزنى، ni: تعداد بذر جوانهزده در روز، n: تعداد كل بذرها مى باشد.

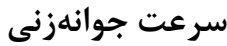

از روز دوم آزمايش، تعداد بذرهاى جوانهزده

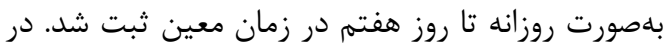

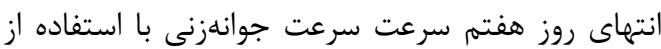

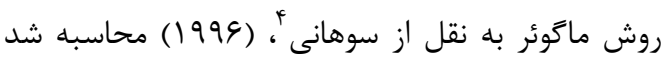

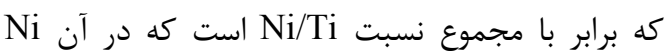
تعداد بذرهاى جوانهزه در هر روز و Ti تعداد باد روزهاى يس إز كاشت بهدست آمد (روز اول تا روز هفتم).

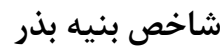

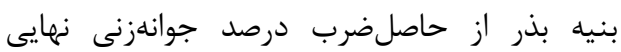

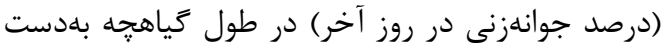

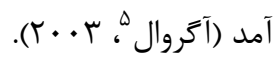

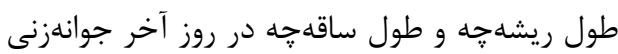
بذرها، بلوسيله خطكش ميلىمترى مورد اندازمخيرى

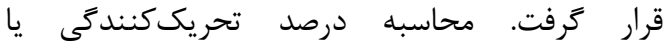

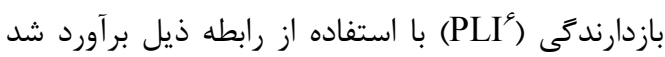

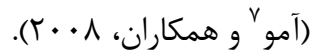$$
\text { PLI }=\left[\left(R_{2-} R_{1}\right) / R_{1}\right] \text { × } 100(r) \text { رابطه }
$$

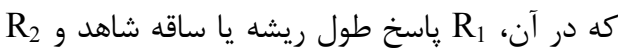

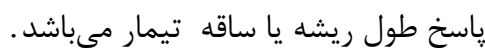

\section{روش اندازهَيرى كلروفيلهاى a b كاروتنوئيدها}

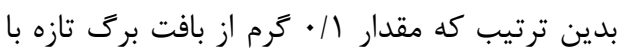
•ا ميلىليتر استون سرد •^ درصد كاملاً له كرديد.

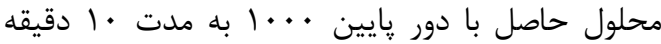
براى جلوكيرى از شكست آللوكميكال سانتريفيوز شد. سبس فاز محلول از فاز جامد جدا ترديد و و با استون سرد • ^ درصد به حجم معين QT ميلى ليتر رسانده شد.

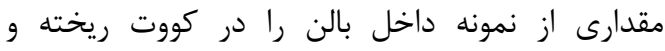

\footnotetext{
${ }^{4}$ Sohani

${ }^{5}$ Agrawal

${ }^{6}$ Percentage Length Inhibition

${ }^{7}$ Amoo
}

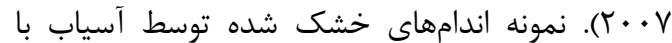
مش 1 به قطعات ريز يودر گرديدند. آزمايش هاى زيستسنج

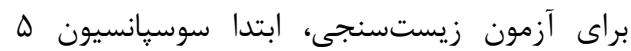
درصد وزنى به حجمى از اندامهاى مورد بررسى علفهي آنهرز

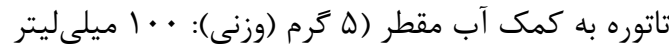

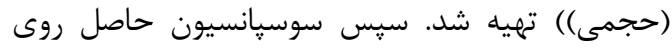

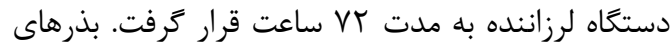
كواهى شده ارقام كندم كوهدشت و N8720 از ايستخاه تحقيقات كشاورزى كنبدكاووس تهيه كرديد كارديد. اين آزمايش بلصورت فاكتوريل در قالب طرح كاملاً تصادفى

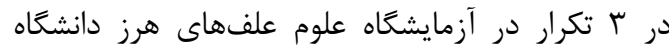

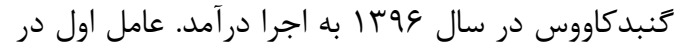
اين آزمايش شامل ارقام كندم در دو سطح (كوهدشت و و

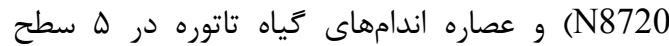
(شاهد، ساقه، برك، ميوه و مخلوطى از آنها) بلهعنوان

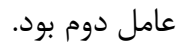
براى آزمون دكرآسيبى، در هريك از سطوح عصاره،

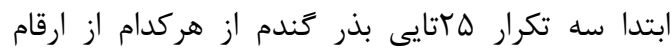

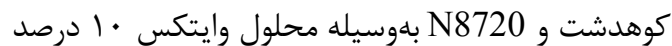
به مدت ب دقيقه ضدعفونى (قربانلى' و و همكاران،

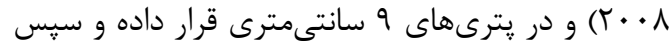
ه ميلىليتر از عصاره مورد نظر بلهطور جداثانه اضافه كرديد. بعد از آن بذرها در اتاقك رشد با تناوب نورى 19

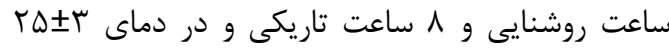
درجه سانتى شدند (كادهو و راجيندر ؟، 1990).

\section{روش اندازهيرى صفات جوانهزنى}

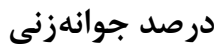
براى درصد جوانهزنى، بذرهاى جوانهزده با ريشه بلندتر از دو ميلىمتر شمارش شدند (هاردخرى و ون درن

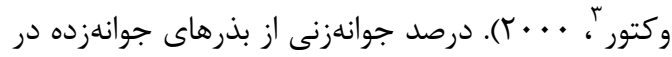
در روز آخر (هفتم) در نظر كرفته و با استفاده از رابطه

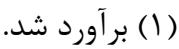

\footnotetext{
${ }^{1}$ Ghorbanli

${ }^{2}$ Cadho and Rajender

${ }^{3}$ Hardgree and Van Vactor
} 


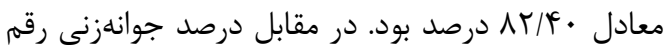
N8720 تحت تيمارهاى مورد بر رسى بجز عصاره برى با دان سطح معنى دارى يكسانى افزايش نشان داد (جدول ؟ ؟).

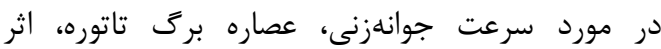

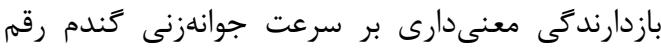

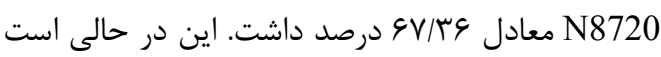
كه اثر ساير تيمارهاى آزمايشى بر اين صفت معنى داد نبود، لذا در كروه يكسانى از لحاظ آمارى قرار كرفتند. أما سرعت جوانهزنى گَندم رقم كوهدشت تحت عصاره

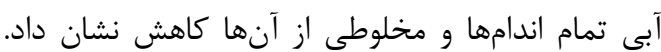

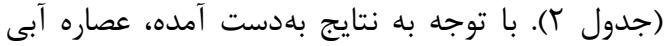
حاصل از علفهرز تاتوره، اثرات متفاوتى بر صفات بات باتئ جوانهزنى ارقام مختلف كندم كوهدشت و N8720 نشان

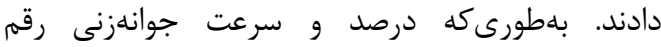
كوهدشت برخلاف رقم N8720 تحت تأثير تمام عصاره

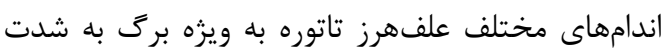

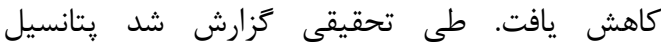
دكرآسيبى يك كياه به عوامل مختلفى شامل كونه

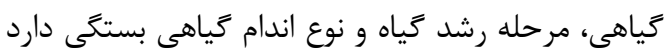

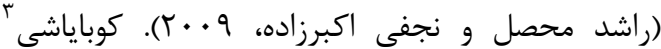

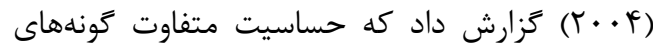

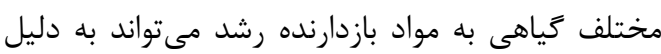
خصوصيات فيزيولوزيكى و و بيوشيميايى متفاوت آن

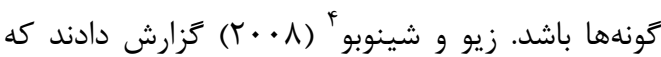

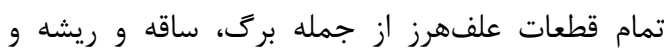

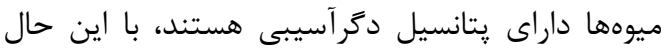

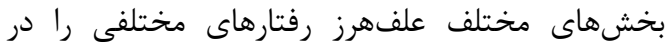
اعمال اثرات دكرآسيب بر محصولات كشاورزى نشان مخدي

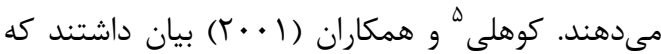
واكنشهاى تحريكى يا بازدارندىى آللوشيميايىها به غلظت ماده شيميايى دريافت شده توسط كياه هدف

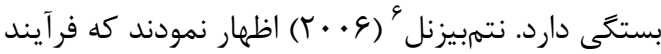

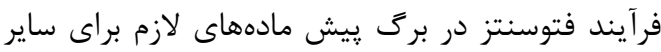

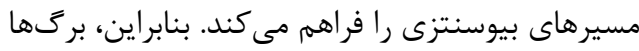

\footnotetext{
${ }^{3}$ Kobayashi

${ }^{4}$ Zuo and Shinobo

${ }^{5}$ Kohli

${ }^{6}$ Ntombizanele
}

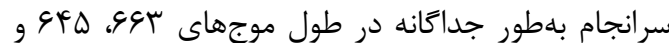
Biochrom نانومتر توسط اسيكتروفتومتر با مدل \&V . libera- S22

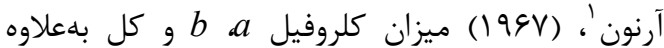
كاروتنوئيدها برحسب ميلى

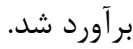

\section{تجزيه و تحليل دادهها}

براى سنجش نرمال بودن دادهها از نرم افزار

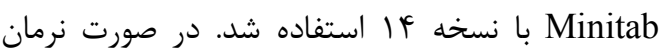
نبودن دادهها، از روش حذف نمودن ميانگين نمونهاى سله كه در دامنه دادهاى ديخر نبود (ميانگين \pm سه بردير

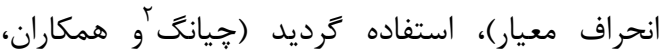

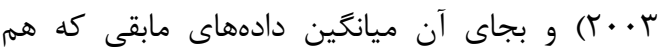
دامنه بودند، آورده شد. سيس تجزيه دادهها توسط مئي نرمافزار SAS و مقايسه ميانگينها با كمك آزمون LSD در سطح احتمال ه درصد انجام شد.

نتايج و بحث نتايج تجزيه واريانس تيمارهاى آزمايشى نشان داد

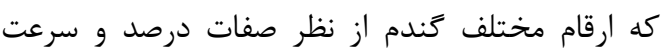
جوانهزنى، طول ساقهجه، شاخص بنيه بذر، ميزان

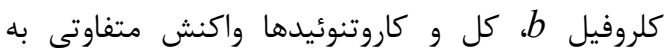
عصاره اندامها در سطح احتمال يك درصد نشان دادند. ياسخ طول ريشهجه و كلروفيل a ارقام كَندم نيز در سطح احتمال ينج درصد معنىدار بود. اين اختلاف براى

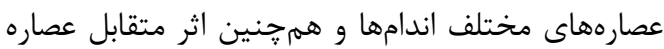

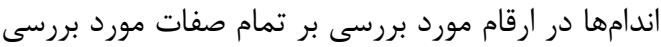

در سطح احتمال يك درصد معنىدار شد (جدول ().

\section{درصد و سرعت جوانهزنى} مقايسه ميانگين اثر متقابل ارقام و عصاره اندامهاى گياهى نشان داد كه درصد جوانهزنى رقم كوهدشت ميان تحت عصاره آبى اندامهاى ساقه، برگ، ميوه و مخلوطى ديى از آنها بهطور معنىدارى در مقايسه با شاهد كاهش

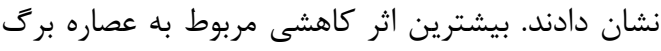

\footnotetext{
${ }^{1}$ Arnon

${ }^{2}$ Chiang
} 
جدول ا- تجزيه واريانس (ميانگين مربعات) جوانهزنى و رنكَيزهاى فتوسنتزى ارقام كندم تحت تأثير عصاره اندامهاى مختلف تاتوره و مخلوطى از آنها

Table 1. Variance analysis (mean square) of germination traits and photosynthetic pigments of wheat cultivars under the effect of various extracts of Datura stramonium and their mixture

\begin{tabular}{|c|c|c|c|c|c|c|c|c|c|c|}
\hline $\begin{array}{l}\text { S.O.V } \\
\text { S.ابع تغييرات }\end{array}$ & $\begin{array}{l}\text { آزادى درجه } \\
\text { DF }\end{array}$ & $\begin{array}{c}\text { درصد جوانهزنى } \\
\text { Germination } \\
\text { percentage }\end{array}$ & 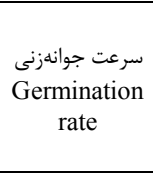 & $\begin{array}{c}\text { ريشه } \\
\text { Root } \\
\text { length }\end{array}$ & $\begin{array}{c}\text { سوله } \\
\text { Shoot } \\
\text { Shoth }\end{array}$ & $\begin{array}{l}\text { شاخص بنيه بذر } \\
\text { Seed vigor } \\
\text { index }\end{array}$ & $\begin{array}{c}\text { ميزان كلروفيل } \\
a \\
\text { Chlorophyll } \\
a \text { content }\end{array}$ & $\begin{array}{c}\text { ميزان كلرفيل } \\
\text { Chlorophyll } \\
\text { b content }\end{array}$ & $\begin{array}{c}\text { ميزان كلرفيل } \\
\text { Total } \\
\text { Tot } \\
\text { chlorophyll } \\
\text { content } \\
\end{array}$ & $\begin{array}{c}\text { كاروتنوئيدها } \\
\text { Carotenoids } \\
\text { content }\end{array}$ \\
\hline رقم Cultivar & 1 & $750.00 * *$ & $1.99 * *$ & $3.51^{*}$ & $73.32 * *$ & $859414.27^{* *}$ & $0.06^{*}$ & $0.20 * *$ & $0.48 * *$ & $0.20 * *$ \\
\hline $\begin{array}{c}\text { عصاره اندام } \\
\text { Organ } \\
\text { extract }\end{array}$ & 4 & $5626.87 * *$ & $3.72 * *$ & $111.55^{* *}$ & $95.28^{* *}$ & $1156948.37 * *$ & $0.63 * *$ & $0.08 * *$ & $1.14 * *$ & $0.35 * *$ \\
\hline $\begin{array}{c}\text { رقم× عصاره اندام } \\
\text { Organ } \\
\text { xextract } \\
\text { Cultivar }\end{array}$ & 4 & $171.67 * *$ & $0.93 * *$ & $21.04 * *$ & $17.75^{* *}$ & $224756.72^{* *}$ & $0.17 * *$ & $0.08 * *$ & $0.36^{* *}$ & $0.14 * *$ \\
\hline خطا Error & 20 & 12.73 & 0.03 & 0.27 & 0.39 & 3452.53 & 0.0057 & 0.00037 & 0.0067 & 0.000043 \\
\hline $\begin{array}{l}\text { ضريب تغييرات } \\
\text { (درصد) } \\
\text { Coefficient } \\
\text { variations } \\
(\%)\end{array}$ & - & 4.56 & 6.82 & 9.52 & 7.47 & 8.01 & 8.38 & 4.68 & 1.20 & 0.84 \\
\hline
\end{tabular}

**,*: Significant at 1 and $5 \%$ probability level, respectively

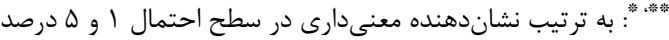

از طول ساقهجه ارقام بود. با توجه به اينكه ريشهجه

اولين قسمتى از بذر در جوانهزنى است كه ظهور مىيابد

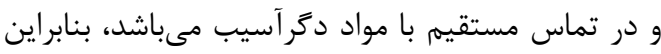

ايجاد اختلال در فعاليت ريشهجه دور دور از انتظار نيست.

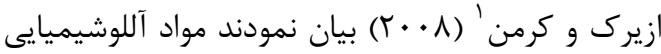

رشد را از طريق تداخل در فرآيندهاى مهرم فيزيولوزيك

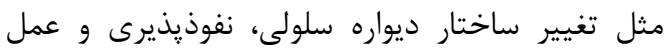

غشاء، جلوگيرى از تقسيم سلولى و فعاليت برخى

آنزيمها و تعادل هورمونهاى خياهى ديرى در هر دو اند اندام

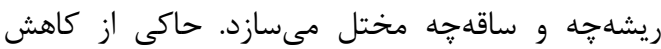

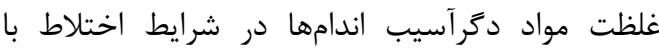

$$
\text { يكديخر است. }
$$

\section{شاخص بنيه بذر}

مقايسه ميانخين تيمارهاى آزمايشى علفهرز تاتوره

نشان داد كه عصاره اندامها و مخلوطى از آنها اثر

كاهشى معنى دارى بر شاخص بنيه بذر رقم كوهدشت

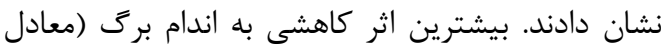

91 درصد) تعلق داشت. اما بررسى واكنش شاخص بنيه

\footnotetext{
${ }^{1}$ Azirak and Karaman
}

جايگاه بيوسنتز تركيبات متنوع و به ويزه متابوليتهاى ثانويه بيشترى هستند و منبع قوىترى از مواد آللوشيميايى محسوب ميىشوند.

\section{طول ريشه جهه و ساقه}

مطابق نتايج، طول ريشهجه ارقام كَندم كوهدشت و و N8720 در ياسخ به عصاره ناشى از اندامهاى مختلف علفهرز تاتوره و مخلوطى از آنها به شدت كاهش نشان داد. بيشترين كاهش معنى دار طول ريشه كاربرد عصاره برگ بر رقم گندم كوهدشت معادل 99/V. اين اندام بر رقم N8720 اختلاف معنى دارى را راندان نداد، لذا در زروه يكسانى قرار گرفتند. در مقابل كمترين ميزان بازدارندگى مربوط به عصاره ميوه در رقم كوهدشت بود (جدول ب). نتايج در مورد طول ساقهجه مشابه طول ريشهجه بود (جدول r). بر اساس نتايج بهدست آمده، طول ريشهجه و ساقهجه رقم كوهدشت نسبت به رقم N8720 بيشتر تحت تأثير تركيبات دخرآسيب حاصل از تيمارهاى آزمايشى قرار كرفت. در اين ميان ميزان كاهش طول ريشهجه بيشتر 
اثر دكرآسيبى كمترى بر طول ريشهجه و ساقهجه هر دو رقم كَندم در مقايسه با برخى از اندامها نشان دادند.

\section{ميزان رنغيزههاى فتوسنتزى كياهجه كَندم}

مطابق جدول r، ارقام مختلف كندم از لحاظ ميزان كلروفيل a پاسخ متفاوتى به تركيبات آللوشيميايى

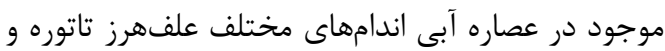

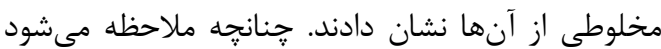
ميزان كلروفيل a رقم N8720 تحت عصاره آبى آنى

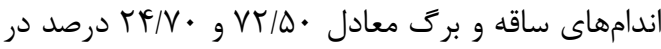
مقايسه با شاهد كاهش نشان داد. همرجنين عصاره

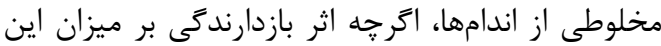

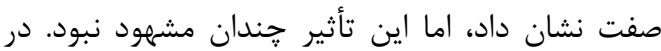

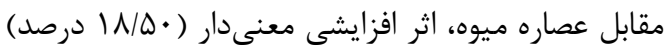
بر ميزان كلروفيل a نشان داد. در مورد رقم كوهدشت، تيمارهاى برك، ميوه و مخلوطى از اندامها، اثر كاهشى دئ دان متفاوتى بر ميزان كلروفيل a اين رقم نشان دادند. اما اثر انر اندان عصاره ساقه بر اين صفت افزايشى بود (جدول بان ك). نتايج در مورد كلروفيل b مشابه كلروفيل a بود (جدول r). اثر افزايشى و كاهشى تركيبات آللوشيميايى حاصل از اندامهاى مختلف گَياه تاتوره بر رنكَيزههاى كَندم رقم كوهدشت و N8720 ممكن است به دليل تفاوت در غلظت آللوكميكالها به ويزه آلكالوئيدها و تركيبات مرتبط با آنها باشد كه به مقدار زيادى در خانواده سولاناسه از جمله كياه تاتوره يافت مىشود. بهطورى كها موجب ياسخ و رفتار متفاوت ارقام مورد آزمايش ترديد.

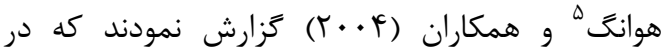
عصاره تاتوره آلكالوئيدهاى مختلفى وجود دارد كه ممكن

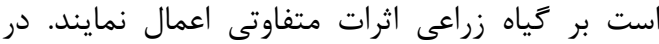

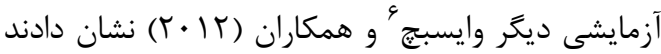
كه ميزان غلظت آلكالوئيدها رابطه مستقيمى با رتانسيل

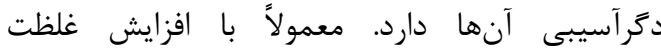
آلكالوئيدها بسته به نوع ماده مؤثره ممكن است دارئ إداى

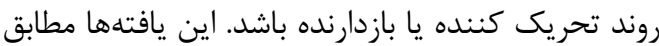
يافتهاى تعدادى ديگر از محققين مىباشد. اسماعيل و

\footnotetext{
${ }^{5}$ Hwang

${ }^{6}$ Weissbach
}

بذر رقم N8720 نشان داد كه تنها دو تيمار برك و مخلوطى از اندامها اثر منفى معنى دار بر اين صفت بهان

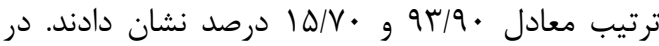
مقابل اندام ميوه اثر افزايشى بر شاخص بنيه بذر اين رقم

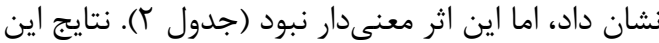
مطالعه نشان داد كه تأثير تركيبات آللوشيميايى روى كياهان هميشه منفى نيست بلكه مواد آللوشيميايى،

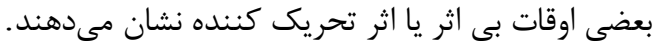

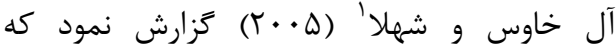
مريستم انتهايى در ريشه به شدت تحت تأثير مواد دكر آسيب قرار مى گيرد و تقريباً رشد آن متوقف مىشود

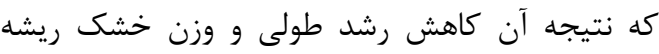

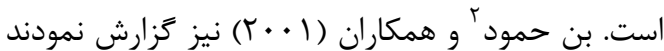
كه مواد آللوشيميايى ميزان اكسين القاء كننده رشد ريشهها را كاهش مىدهند. اين تركيبات با ممانعت از جذب عناصر غذايى و با دخالت مستقيم در تنفس (فسفريلاسيون اكسيداتيو) موجب كاهش رشد مىشوند.

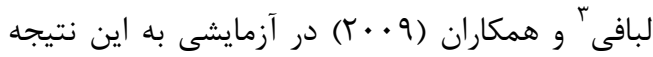
رسيدند كه طول ريشهجه كندم رقم روشن به عصاره

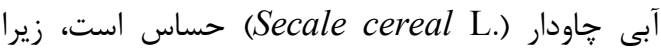
بيشتر در معرض مواد آللوشيميايى قرار مى كيرد. در اين

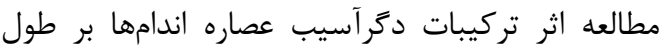
ريشهجه و ساقه קه بيشتر از درصد جوانهزنى بوده است.

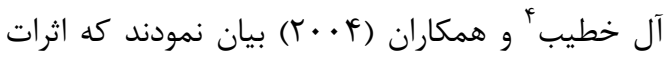
آشكار تركيبات آللوشيميايى در مرحله جوانهزنى شامل

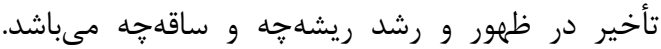

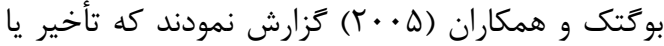

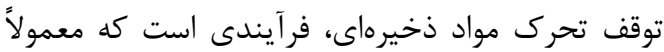
به سرعت در طى جوانهزنى بذر اتفاق مى افتد، مىتواند منجر به كمبود فرآوردههاى تنفسى كردد و در نهايت منجر به كمبود مستمر ATP در بذرهايى كه در معرض فرد مواد آللوشيميايى قرار كرفتهاند، شود. بى نظمى ندى در ميزان تنفس منجر به ايجاد محدوديت انرزى متابوليك و در نهايت كاهش جوانهزنى و رشد گياهجه مى تردئ. نتايج اين مطالعه همرجنين نشان داد مخلوطى از اندامها

\footnotetext{
${ }^{1}$ EL-Khawes and Shehela

${ }^{2}$ Ben-Hammouda

${ }^{3}$ Labbafy

${ }^{4}$ El-Khatib
} 


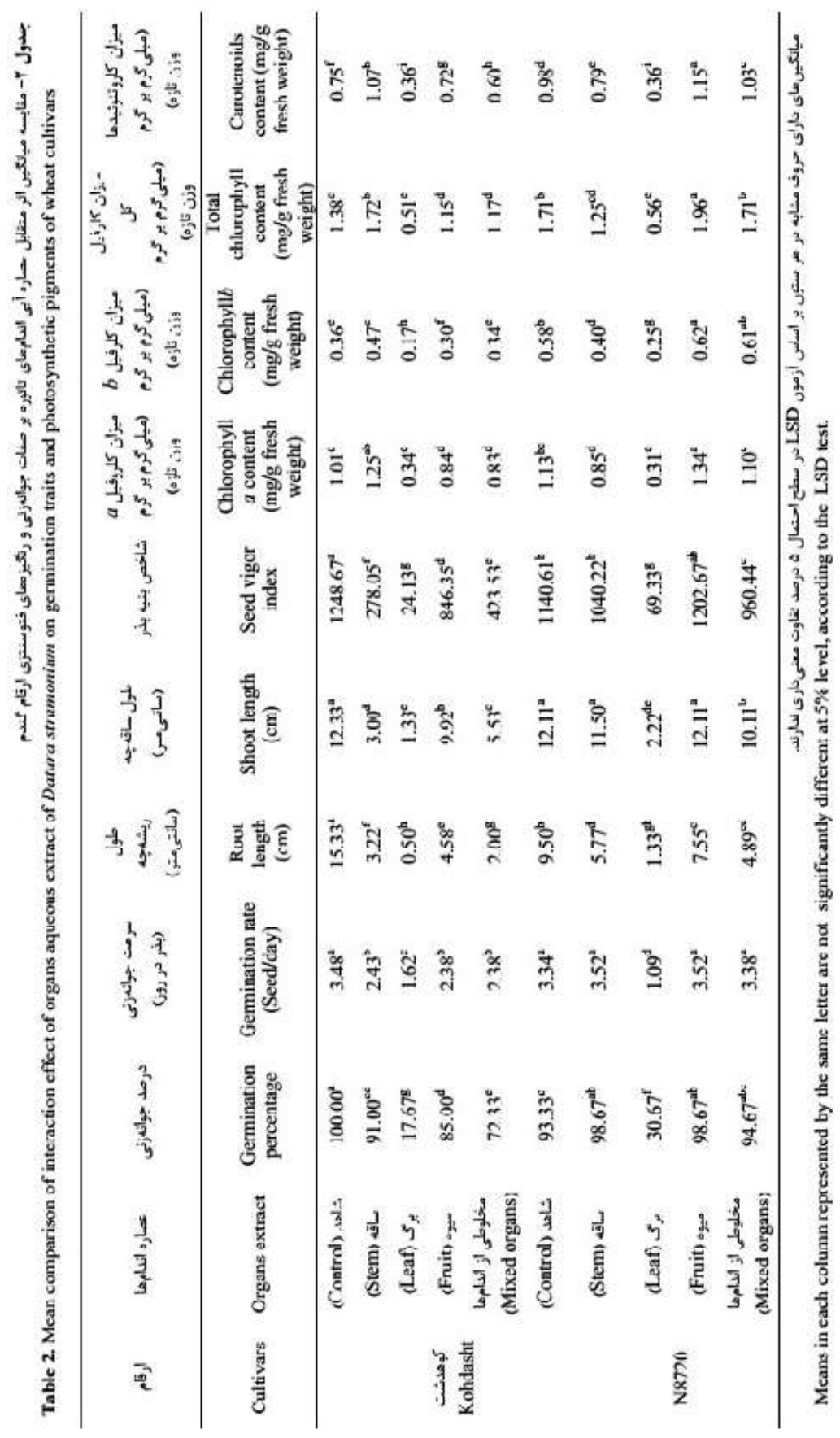


(l) يكى از دلايل كاهش غلظت ميزان كلروفيل تحت كاربرد عصارهها را بهواسطه افزايش ميزان فعاليت

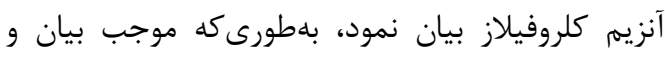

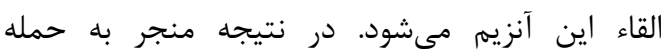
راديكالهاى آزاد توليدى مانند سويراكسيد، هيدروكسى،

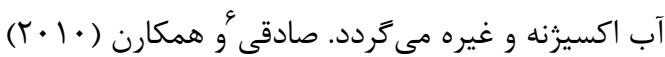

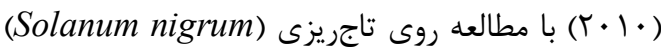
كزارش كردند در بين اندامهاى مختلف، عصاره برى

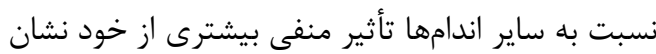
داد. نتايج در مورد ميزان رنكَيزه كاروتنوئيدها مشابه بانيه

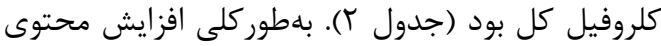

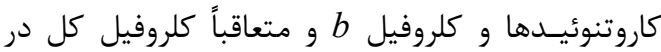

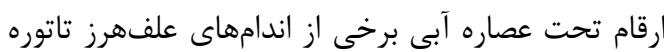

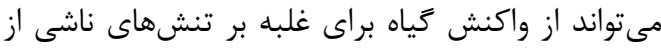
تركيبات آللوشيميايى با توجه به نقش محاظتي آنى آنها

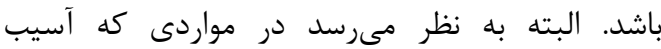
تركيبات آللوشيميايى بسيار بالا است، اين سيستم قادر آدراد

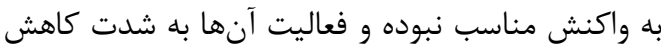
مى يابد.

\section{نتيجه كيرى}

در مجموع بررسى واكنش ارقام كندم كوهدشت و

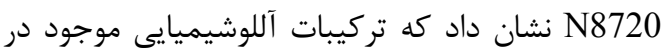
اندامهاى مختلف علفهرز تاتوره بر جنبههاى متعددى از صفات جوانهزنى و رنخيزهاى كلروفيلى و كاروتنوئيدى

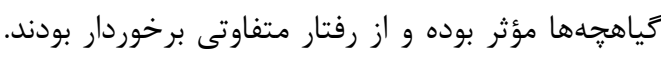

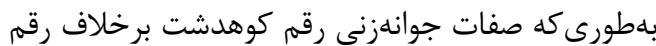

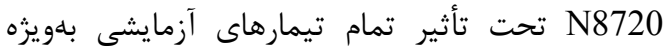
برك به شدت كاهش يافت. همرجنين طول ريشه تهاته

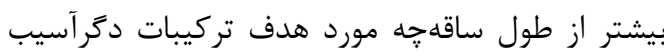
اندامها و مخلوطى از آنها قرار كرفت. در اين مطالعه،

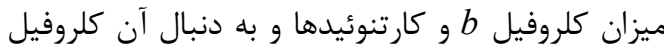
كل رقم كوهدشت و N8720 به ترتيب تحت عصاره آبى اندامهاى ساقه و ميوه علفهرز تاتوره افزايش نشان داد. در مقابل اثر ساير عصاره اندامها كاهشى بود. اثر كاهشى عانى رنخيزههاى حفاظتى مى تواند به دليل عدم سنتز كافى و واني

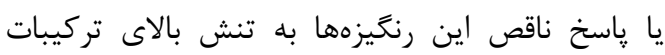

${ }^{6}$ Sadeghi

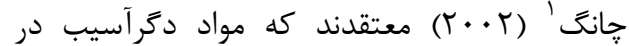
غلظتهاى يايين ممكن است اثرات منفى يا مثبت بر

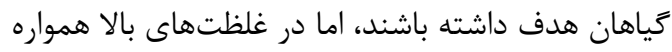

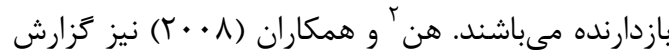

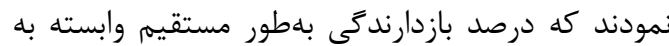

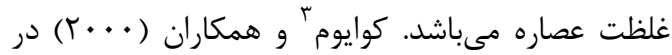

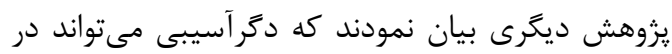

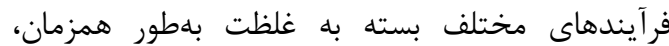
تأثيراتى منفى و مثبتى را اعمال كند.

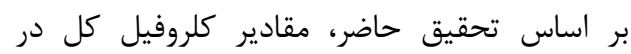
كياهجههاى كندم ارقام كوهدشت و N8720 به ترتيب

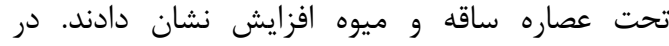

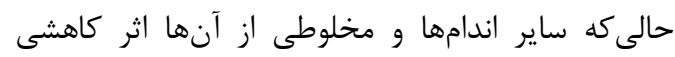
متفاوتى بر صفات مورد بررسى داشتند. بيشترين اثر الثران كاهشى مربوط به عصاره بركى بر روى رقم كوهدشت مرد برد معادل \& •/ م ع درصد بود كه از لحاظ آمارى با اثر عصاره برك بر رقم N8720 اختلاف معنى دارى را نشان ندادند،

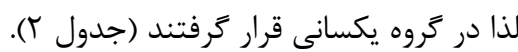

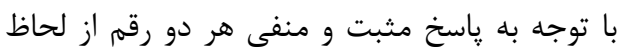

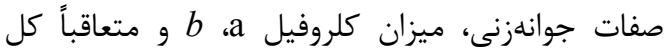

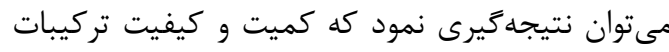

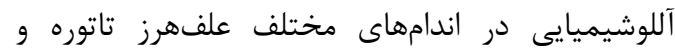

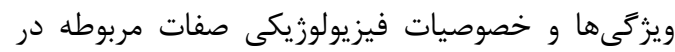
ارقام مورد بررسى موجب مقاومت و حساسيت حسيت در

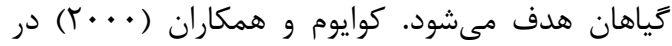
يزوهشى بيان نمودند كه تركيبات آللوشيميايى مى هواند

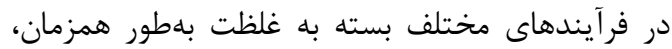

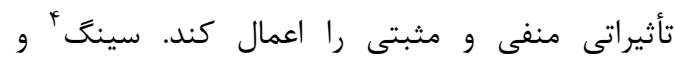

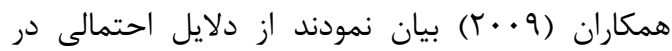

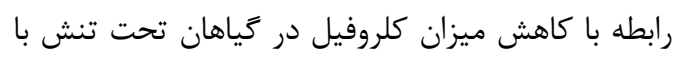
دكرآسيبى، تغيير متابوليسم نيتروزن است. تنشهاى زيستى و غيرزيستى موجب مى شيود كه كلوتامات كه

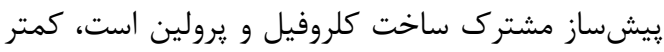

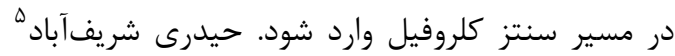

\footnotetext{
${ }^{1}$ Ismail and Chong

${ }^{2}$ Han

${ }^{3}$ Quayyum

${ }_{5}^{4}$ Singh

${ }^{5}$ Hidari Sharifabad
} 


$$
\begin{aligned}
& \text { امر نياز به تجزيه فيتوشيميايى تركيبات حاصل از اين } \\
& \text { دكر آسيب عصاره اندامها باشد. با توجه به حساسيت رقم } \\
& \text { علفهرز مىباشد. }
\end{aligned}
$$

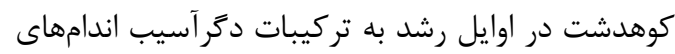

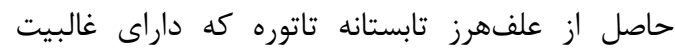

$$
\begin{aligned}
& \text { سياسگزارى }
\end{aligned}
$$

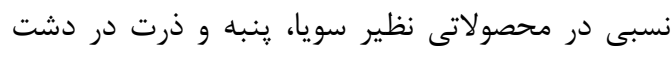

$$
\begin{aligned}
& \text { نويسندكان از كارشناسان محترم آزمايشكاههاى }
\end{aligned}
$$

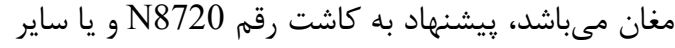

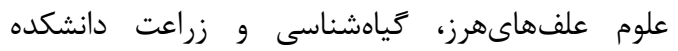

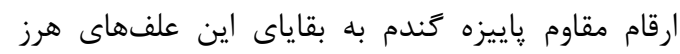

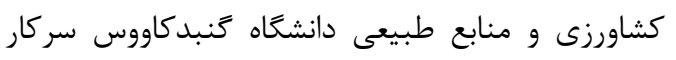

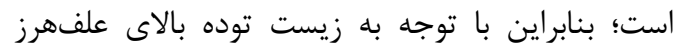

$$
\begin{aligned}
& \text { خانم مهندس ليلما سراوانى و حسين بابايى بلواسطه } \\
& \text { مساعدت و تسهيل در روند اجراى اين آزمايش صميمانه }
\end{aligned}
$$

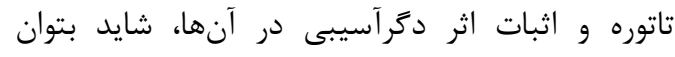

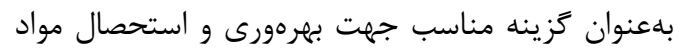

$$
\begin{aligned}
& \text { تقدير و تشكر مىنمايند. } \\
& \text { مؤثره از آنها، مورد استفاده قرار كيرد. جهن مناست تحقق اين }
\end{aligned}
$$

Agrawal, R. 2003. Seed technology. Pub. Co. PVT. LTD. New Delhi. India.

Amoo, S.O., Ojo, A.U., and Van Staden, J. 2008. Allelopathic potential of Tetrapleura tetraptera leaf extracts on early seedling growth of five agricultural crops. South African Journal of Botany, 74: 149-152. https://doi.org/10.1016/j.sajb.2007.08.010

Arnon, A.N. 1967. Method of extraction of chlorophyll in the plants. Agronomy Journal, 23: 112126.

Azirak, S., and Karaman, S. 2008. Allelopathic effect of some essential oils and components on germination of weed species. Acta Agriculturae, 58: 88-92. https://doi.org/10.1080/09064710701228353

Ben-Hammouda, M., Ghorbal, H., Kremer, R.J., and Oueslati, O. 2001. Allelopathic effects of barley extracts on germination and seedling growth of bread and durum wheat. Agronomie, 21: 65-71. https://doi.org/10.1051/agro:2001109

Bogatek, R., Gniazdowka, A., Stepien, J., and Kupidlowska, E. 2005. Convolvulus arvensis allelochemicals modeofaction in germination wheat seeds. Proceedings of the 4th world Congress on Allelopathy, (August 11-14), Wagga Wagga. 263-266.

Bourgaud, F., Gravot, A., and Miles, S. 2001. Production of plant secondary metabolites: a historical perspective. Plant Science, 161(5): 839-851. https://doi.org/10.1016/S01689452(01)00490-3

Caceres, A. 2000. Calidad de la material prima para la elaboracion de productos fitofarma ceuticas. Primer CongresoInternational FITO 2000. Por la investigacion, conservacion y diffusion del conocimiento de las plantas medicinals 27-30 de septiembre, 2000, Lima, Peru.

Cadho, K.L., and Rajender, G. 1995. Advances in horticulture medicinal and aromatic plants. Medicinal and Aromatic Plants, 11: 1-43.

Chiang, L.H., Pell, R.J., and Seasholtz, M.B. 2003. Exploring process data with the use of robust outlier detection algorithms. Journal of Process Control, 13: 437-449. https://doi.org/10.1016/S0959-1524(02)00068-9

El-Khatib, A.A., Hegazy, A.K. and Gala, H.K. 2004. Does allelopathy have a role in the ecology of Chenopodium murale? Annual Botany Fennici, 41: 37-45.

EL-Khawes, S., and Shehela, M.M. 2005. The allelopathic potentialities of Acacia and Eucalyptus prostrate on monocot (Zea mays L.) and dicot (Phaseeolus vulgaris L.). Plant Biotechnology, 4(1): 23-24. 
El-Rokiek, K.G.I., and Eid, R.A. 2009. Allelopathic effect of Eucalyptus citriodora on Amaryllis and associated grassy weed. Planta Daninha, 27: 887-899. https://doi.org/10.1590/S010083582009000500002

FAO. 2010. The Lurking menace of weeds. http://www.fao.org/news/story/en/item/29402/icode/. 30.

Ghareman, A. 1994-1996. Colored flora of Iran (1st and 13th wrapper). Publication of national association of conservation of human environment in partnership with Tehran university and Research Institute of Forests and Rangelands. [In Persian with English Summary].

Ghareman, A. 1994. Basic code for families and genera of Flora of Iran. Publication of Research Institute of Forests and Rangelands. [In Persian with English Summary].

Ghorbanli, M.L., Bakhshi Khaniki, Gh.R., and Sojahi, A.A. 2008. Study of allelopathic effect of Artemisia siberi on two seedlings of Avena lodoviciana and Amaranthus retrofexus. PajouheshVa-Sazandegi in Natural Resources, 79: 129-134. [In Persian with English Summary].

Han, C.M., Pan, K.W., Wu, N., Wang, J.C., and Li, W. 2008. Allelopathic effect of ginger on seed germination and seedling growth of soybean and chive. Scientia Horticulturae Journal, 116: 330-36. https://doi.org/10.1016/j.scienta.2008.01.005

Hardgree, S.P., and Van Vactor, S.S. 2000. Germination and emergence of primed grass seeds under field and simulated-field temperature regimes. Annals of Botany, 85(3): 379-390. https://doi.org/10.1006/anbo.1999.1076

Hejazi, H.H. 2001. Allelopathy (autotoxicity and hetrotoxicity). Tehran university press. 181p. [In Persian].

Hidari Sharifabad, H. 2001. Plant and Salinity. Publication of Research Institute of Forests and Rangelands, 98p. [In Persian].

Hwang, B.Y., Su, B.N., Chai, H., Mi, Q., Kardono, L.B.S., and Afriastini, J.J. 2004. Silvestrol and episilvestrol, potential anticancer rocaglate derivatives from Aglaia silvestris. Journal of Organic Chemistry, 69(10): 2210-2218. https://doi.org/10.1021/jo040120f PMid:15132542

Ismail, B.S., and Chong, T.V. 2002. Effect of aqueous extract and decomposition of Mikania micrantha on selected agronomic crops. Weed Biology and Management, 2: 31-38. https://doi.org/10.1046/j.1445-6664.2002.00045.x

Kobayashi, K. 2004. Factors affecting phytotoxic activity of allelochemicals in soil. Weed Biology and Management, 4: 1-7. https://doi.org/10.1111/j.1445-6664.2003.00112.x

Kohli, R.K., Singh, H.P., and Batish, D.R. 2001. Allelopathy in Agro Ecosystems. Food Products Press, USA, 447p.

Labbafy, M. R., Mighani, F., Hejazy, A., Khalaj, H., Baghestani, A.M., Allahdady, I., and Mehr Afarin, A. 2009. Study of allelopathic interaction of wheat (Triticum aestivum L.) and rye (Secale cereal L.) using Equal-Compartment-Agar method. Asian Journal of Agricultural Sciences, 1(2): 25-28.

Levitt, J., and Lovett, J. 1984. Activity of allelochemicals of Datura stramonium L. in contrasting soil types. Plant and Soil, 190: 282-289.

Martinov, M., Oztekin, S. and Muller, J. 2007. Drying. In: Oztekin, S. and Martinov, M. (Eds.). Medicinal and Aromatic Crops. CRC Press, United States of America, 320p.

Min, A., Liu, D. L., Johnson, I. R. and Lovett, J. V. 2003. Mathematical modeling of allelopathy: The dynamics of allelochemicals from living plants in the environment. Ecological Modelling, 161:53-66. https://doi.org/10.1016/S0304-3800(02)00289-2

Min Bashi, M., Zand, E., and Mighani, F. 2011. Non chemical management of weeds. Principals, concepts and technology (Translate). Jahad Daneshgahi of Mashhad, 334p. [In Persian]. 
Ntombizanele, P.M. 2006. Allelopathic interference of silver nightshade (Solanum elaeagnifolium Cav.) with the early growth of cotton (Gossypium hirsutum L.), M.Sc. Thesis University of Pretoria, South Africa.

Oudhia, P. 1998. Germination and seedling vigour of chickpea as affected by allelopathy of Datura stramonium L. International Chickpea and Pigeonpea Newsletter, 10: 31-33.

Quayyum, H.A., Mallik, A.U., Leach, D.M., and Gottardo, C. 2000. Growth inhibitory effects of nutgrass (Cyperus rotundus) on rice (Oryza sativa) seedlings. Journal of Chemical Ecology, 26: 2221-2231. https://doi.org/10.1023/A:1005532802836

Rashed Mohassel M.H., Najafi Akbarzadeh M.D. 2009. Biology and weed control. Second edition, Ferdowsi University of Mashhad, Mashhad. 404 p. [In Persian].

Sadeghi, S., Rahnavard, A., and Ashrafi, Z.Y. 2010. Allelopathie effect of Helianthus annuus on Solanum nigrum seed germination and growth in laboratory condition. Journal of Horticultural Science and Ornamental Plants, 2(1): 32-37.

Safahani Langeroudi, R., Farhodi, R., Soltani, C., and Sakenin, H. 2009. Hetrotoxicity effect of aqouesextract of several weed species on germination and seedling growth of wheat. Journal of Agricultural Researche, 3: 83-93. [In Persian with English Summary].

Shajih, E., 2006. Study of hetrotoxicity effects of extract and plant residues of Datura stramonium and Xanthium spp on germination and seedling growt of corn and canola in laboratory and green house. MSc. thesis. Kerman Shahid Bahonar University, Iran, 165p. [In Persian with English Summary].

Shen, H., Guo, H. and Huang, G. 2009. Allelopathy of different plants on wheat, cucumber and radish seedlings 2005. Pubmed online. Available at: URL: http: // www.pubmed.gov/, Accessed Juluy 24.

Singh, A., Singh, D. and Singh, N.B. 2009. Allelochemical stress produced by aqueous leachate of Nicotiana plumbaginifolia Viv. Plant Growth Regulation, 58: 163-171. https://doi.org/10.1007/s10725-009-9364-1

Sohani, M. 1996. Control and certified seed. Guilan University press. 166p. [In Persian].

Soltys, D., Krasuska, U., Bogatek, R., and Gniazdowska, A. 2013. Allelochemicals as bioherbicide-present and perspectives, Herbicides, Andrew J. Price and Jessica A. Kelton, IntechOpen, DOI: 10.5772/56185. Available from: https://www.intechopen.com/books/herbicides-current-research-and-case-studies-inuse/allelochemicals-as-bioherbicides-present-and-perspectives.

Sondhia, S., and Swain, D. 2002. Allelopathic effects of Datura stramonium L. on rice and Echinochloa colonum. Alellopathy Journal, 10(2): 133-140.

Tigre, R.C., Silva, N.H., Santos, M.G., Honda, N.K., Falcao, E.P.S., and Pereira, E.C. 2012. Allelopathic and bioherbicidal potential of Cladonia verticillaris on the germination and growth of lactuca sativa. Ecotoxicology and Environmental Safety, 84: 125-132. https://doi.org/10.1016/j.ecoenv.2012.06.026 PMid:22835725

Weissbach, A., Bechemin, C., Genauzeau, S., Rudstrom, M., and Legrand, C. 2012. Impact of Alexandrium tamarense allelochemicals on DOM dynamics in an estuarine microbial community. Harmful Algae, 22: 18-61. https://doi.org/10.1016/j.hal.2011.10.003

Zuo, Y.M., and Shinobu, I. 2008. Ecological adaptation of weed biodiversity to the allelopatic rank of the stubble of different wheat genotypes in a maize field. Weed Biology and Management, 8: 161-171. https://doi.org/10.1111/j.1445-6664.2008.00292.x 


\title{
Evaluating Hetrotoxic Potential of Aqueous Extract of Datura stramonium Shoots on Germination Traits and Content of Photosynthetic Pigments of Wheat Cultivars
}

\author{
Vahdat Rajaei ${ }^{1}$, Ebrahim Gholamalipour Alamdari ${ }^{2, *}$, Zeinab Avarseji ${ }^{2}$, Masuome \\ Naeimi $^{2}$
}

\section{Extended abstract}

Introduction: Given the known harmful effects of synthetic herbicides, nowadays the utilization of hetrotoxic characteristics of hetrotoxic plants can have a very important role in weeds management and control. In fact chemical compounds, released through roots, stems, leaves, flowers, seed pollen, fruits and seeds can be used as bio-herbicides and bio-pesticides. The purpose of this study was evaluation of the effects of hetrotoxicity potentials of Datura stramonium L. shoots on germination traits and photosynthetic pigments of wheat cultivars.

Materials and Methods: An experiment was conducted to evaluate hetrotoxicity potential effects of aqueous extract of different organs of Datura stramonium L. such as stems, leaves, fruits and their mixture on germination traits and photosynthetic pigments of two cultivars of wheat (Kohdasht and N8720) as a factorial experiment based on a completely randomized design with three replications in Weeds Science Laboratory of Gonbad-e- Kavous University in 2017. Datura stramonium shoots were collected at fruit formation stage in the Moghan Plain and were subsequently separated into stems, leaves and fruits. Five ml of the extracts in question and their mixture were added to 25 disinfected seeds of the cultivars under the study separately.

Results: The results showed that wheat cultivars had different responses to the organ extract and this difference was also significant for various organ extracts as well as the interaction effect of cultivars in organ extracts. Mean comparison of interaction of cultivars and organs showed that germination percentage of the Kohdasht cultivar decreased under the experimental treatments. The highest decrease was obtained in the leaf extract, which was about $98.33 \%$. However, stem, fruit and mixed organs increased the germination percentage of $\mathrm{N} 8720$, which were about $5.72,5.72$ and $1.41 \%$, respectively. The result of the germination rate was similar to that of germination. Radicle and shoot length of both cultivars decreased under experimental treatments. Leaf extract had the highest inhibitory effects on radicle and shoot length, which were about 96.70 and $89.21 \%$, respectively. Content of total chlorophyll of both cultivars of Kohdast and N8720 increased under aqueous extract of stem (24.64\%) and fruit (14.62\%). Nevertheless, extract of other organs and their mixture decreased the trait of interest. The result obtained for carotenoid was also the same as that one obtained for total chlorophyll. The speculation is differences in allelochemical concentration in various organs of Datura stramonium and physiological characteristics of the traits studies in cultivars caused the difference.

Conclusions: Given the results, use of Datura stramonium biomass, especially the leaf, is suggested as a natural herbicide, which is non-chemical management strategy. To accomplish this, it is necessary to analyze phytochemical compounds of this weed.

Keywords: Carotenoids, Hetrotoxicity, Kohdasht and N8720 cultivars, Leaf organ, Seed vigor, Total chlorophyll.

\section{Highlights:}

1- Extract of different parts of Datura stramonium weed had different effects on germination traits and content of chlorophyll and carotenoids of both Kohdast and N8720 cultivars.

2- Leaf extract of Datura stramonium significantly decreased germination traits and content of chlorophyll and carotenoids of seedlings of the Kohdasht cultivar.

3- Use of Datura stramonium can be a good option for introduction of natural herbicides.

1 Graduated student of Identification and Weeds Control, College of Agriculture and Natural Resources, Gonbad Kavous University, http://dorl.net/dor/20.1001.1.23831251.1397.5.2.5.0 Gonbad Kavous, Iran

2 Assistance professor of plant production Department, College of Agriculture and Natural Resources, Gonbad Kavous University, Gonbad Kavous,Iran

*Corresponding author, E-mail address: eg.alamdari@gonbad.ac.ir

http://dx.doi.org/10.29252/yujs.5.2.29

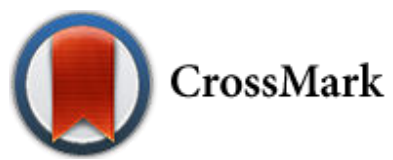

